\title{
Perancangan Iklan Instastory Daily Sebagai Pesan Bijak Berkendara Di Jalan Raya
}

\author{
Diptya Aristo Sahisnu \\ Program Pascasarjana Institut Seni Indonesia Yogyakarta \\ aristo.artwork99@gmail.com
}

\begin{abstract}
The news of the traffic is very updated Lot of the day, from the violation of the community to inform social media, namely to remind the danger of violations of people in the highway. Congestion becomes a perbicangan and the idea that is often displaced in the group as well as lacking the wise attitude of driving on the highway.

Instastory daily $A D$ Design is the most suitable approach for communicating the wise message of this drive in Hengel, quality, and interrated Instastrory has the advantage of interactive stuff, method of 101 design method by Vijay Kumar Liquid One of the literary solver to be able to visualize sponsored advertisements, as well as communicative because it can do in dailly.

This ad design titled "Pesan Bijak Bijak berkendara di Jalan Raya " will be able to visualize a wise message of driving in 15 seconds and can be a profile Instagram account. A person can Mauri a registered ad is published through an Instagram profile with a spotlight menu. This promotion will not only be sponsored but also used in social promotion as a community with optimal results.
\end{abstract}

Keywords: Wise, drive, traffic, social media, Instagram, instastory, community, caring, attitude, social, communication.

Relevance to Visual Communication Design Practice: As a reference and alternative visual communication design solutions for designers and researchers, for academic or practical needs.

\section{LATAR BELAKANG MASALAH}

Sosial Media sangatlah banyak di era dunia digital saat ini, banyak juga menimbulkan peran positif dan negatif. Berangkat dari kasus negatif yang ada di sosial media seperti halnya dalam grup info cegatan jogja atau lebih dikenal dengan ICJ. Berita tentang lalu lintas sangatlah update setiap harinya, dari mulai pelanggaran yang dilakukan masyarakat untuk dinformasikan ke sosial media hingga saling mengingatkan bahaya dari pelanggaran yang dilakukan orang di jalan raya. Keresahan kemacetan menjadi perbicangan dan gagasan yang sering diungah dalam grup serta kurang bijaknya para pengguna jalan raya.

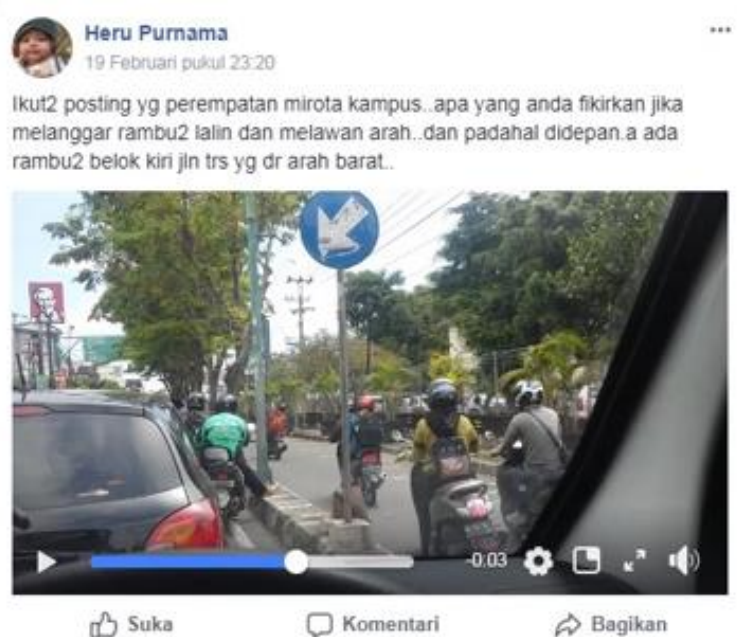

Gambar 1 "pelanggaran lalu lintas di Yogyakarta" Sumber : Grup Facebook ICJ 
Contoh kasus disebuah postingan Heru Purnama merupakan hasil tangkapan kamera bahwa keresahan warga Yogyakarta dengan adanya pelaku pelanggaran penggunaaan jalan di lalulintas. Sangatlah tidak mudah untuk menimbulkan sikap peduli dengan pengguna jalan lain bahkan pengguna lawan arah untuk memberikan haknya. Tingkat kesadaran yang rendah ini mulai diamati oleh masyarakat sehingga yang ada hanya hasil tindakan laporan bukan memberikan informasi namun saling menyalahkan keberadaan pelaku. Jalan raya itu milik masyarakat bersama, namun ada undang-undang yang mengatur peraturan di jalan raya. UU no 22 tahun 2009 mengantur tentang lalu-lintas dan angkutan jalan. Sebagai warga Indonesia yang menggunakan jalan raya hendaklah tertib dan menaati peraturan yang sudah diterapkan dan digunakan sehingga dapat memberikan dampak positif bagi berkembangnya lalu-lintas di jalan raya Yogyakarta.

Menimbulkan kesadaran akan bijak menggunakan jalan raya menjadi penting untuk pembelajaran bersama agar masyarakat mampu menciptakan kenyamanan dan rasa saling menghargai saat berkendara dijalan Raya. Saat melalukan riset tentang lalu lintas Nampak kegelisahan yang benar-benar di hadapi oleh masyarakat, dengan riset simpel tentang berkendara di jalan raya, responden memberikan sesi tanya jawab beberapa pertanyaan melalui story instagram yang dapat digunakan untuk sesi tanya jawab.

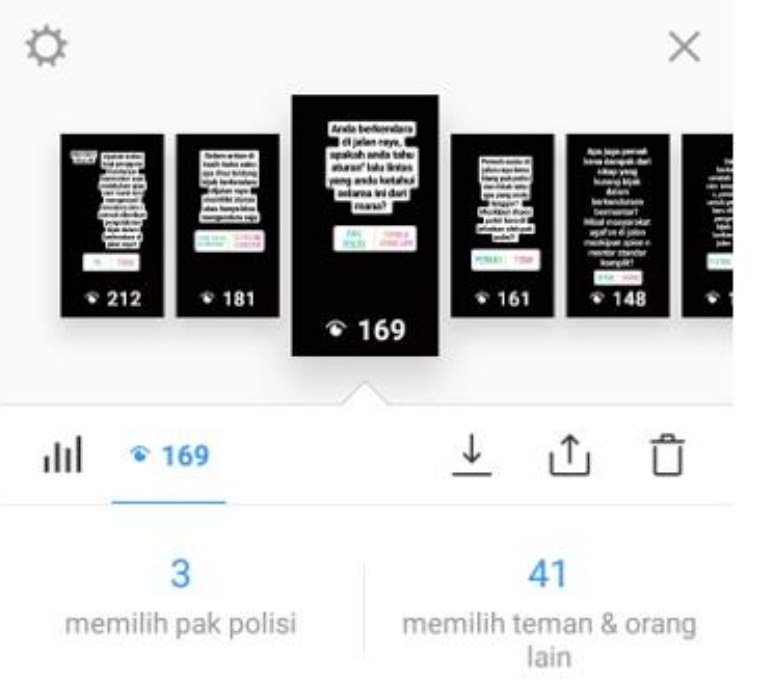

Bagikan Hasil

Gambar 2 "Diptya Aristo S, Kuisoner" Sumber : Story Instragam Personal

Saat dalam melakukan riset diatas perancang menanyakan beberapa hal namun yang sangatlah menarik ketika membahas tentang bagaimana anda tahu peraturan lalu lintas dan dari siapa anda mengetahuinya? Disini sangatlah memprihatinkan ketika para pelaku pengguna jalan raya sudah memiliki surat izin menggemudi namun tidak tahu akan peraturan lalu lintas. Para responden yang menjawab dari 169 viewers dan yang memberikan jawaban 44 orang. Dengan jawaban 3 mengetahui dari Pak Polisi dan 41 mengetahuinya dari teman-teman dan orang tua.

Penggunaan jalan raya utama yang dapat mengakses menuju satu tempat ke tempat yang lain bisa dinikmati oleh masyarakat dan kendaraan bermotor karena semua jalan raya dibiayai atau fasilitasi oleh perusahaan Negara, namun semua pemakaian jalan raya memiliki undang- 
udang pengangkutan. Penggunaan dijalan raya memang sangatlah padat, menimbulkan kesadaran sangatlah tidak mudah, ketika peran polisi di lalu-lintas itu untuk mengawasi serta menjaga arus jalan agar tetap aman dan terkenali. Peran masyarakat pun di butuhkan untuk samasama memahami aturan-autran dalam berkendara untuk lebih bijak lagi berkendara di jalan raya.

\section{RUMUSAN MASALAH}

Perancangan iklan instastory dailly ini dalam kampanye \#bijakberkendarayk untuk masyarakat yang menggunakan jalan raya diharapkan mampu menimbulkan tingkat kesadaran dan solusi permasalahan yang telah dipaparkan sebelumnya. Rumusan masalah perancangan ini adalah "bagaimana merancang iklan instastory daily sebagai pesan bijak berkendara di jalan raya"

\section{TUJUAN DAN MANFAAT}

\section{Tujuan}

Bijak dalam menggunakan jalan raya adalah kunci bagaimana masyarakat mampu menghargai para pengguna jalan lainya. Perancangan ini bertujuan untuk dapat menjembatani pertaturan di lalu-lintas agar mudah dimengeti dan mampu dipahami oleh masyarakat terutama di Kota Yogyakarta agar terciptanya suasana jalan raya yang saling menghargai antar pengguna jalan raya.

\section{Manfaat Praktis}

1. Perancangan iklan instastory daily \#bijakberkendara untuk mahsiswa bijak berkendara dapat menjadi refrensi dan kajian ilmu perancangan desain komunikasi visual, khususnya perancangan iklan guna perkembangan iklan dalam bentuk instastory kampanye di sosial media.

2. Perancang iklan instastory dailly \#bijakberkendara untuk masyarakat dapat mendukung pemerintah, dalam hal ini adalah menciptakan kenyamanan di ruang publik saat berkendara dan menimbulkan kesadaran dari sikap bijak berkendara.

\section{Manfaat Teroritis}

1. Sebagai sumber referensi dan kajian ilmu perancangan desain komunikasi visual, yakni perancangan yang bertujuan untuk memecahkan permasalahan dengan perilaku sosial.

2. Sebagai sumber referensi dan alternatif solusi permasalahan desain komunikasi visual bagi perancang maupun peneliti karya desain.

\section{METODE PERANCANGAN}

Dalam proses perancangan ini mengadopsi bagaimana "vijay kumar 101 metode desain" mengambil unsur melakukan tujuh mode proses desain inovasi, diantaranya memahami tujuan, mengetahui konteks, mengenal masyarakat, menyusun gagasan, mengejokirasi konsep, menyusun solusi, dan merealisasikan penawaran. Sehingga step by step yang dapat membantu desainer untuk menyelesaikan perancangan hingga final designs. 


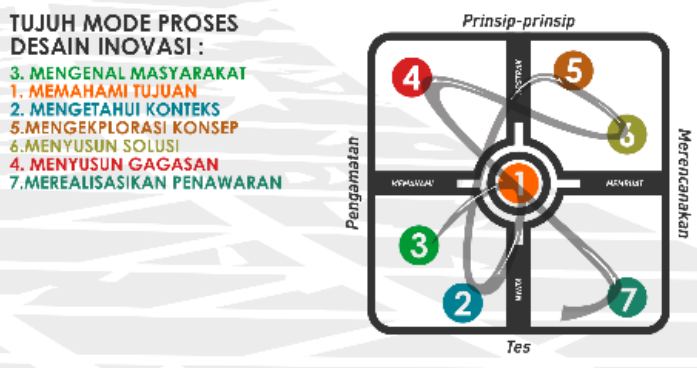

Gambar 3 "Tujuh Mode Proses Desain inovasi" Sumber: 101 metode desain)

\section{Mengenal Masyarakat}

Proses mengamati awalnya perancang lakukan melalui sosial media yaitu facebook, dengan adanya grup atau komunitas yang dapat memberikan ruang bagi masyarakat sosial media terutama pengguna aktif dalam sosial media, ini dapat menimbulkan respon positif dan negatif.

Mencoba riset dengan menggunakan fasilitas instagram melalui \#jejak pendapat yang dapat membantu perancang untuk bahan layaknya perciptaan ini diwujudkan. Dengan memberikan beberapa kuisoner yang dapat langsung di respond oleh followers perancang harapannya mendapatkan data dari orang terdekat tentang bijak berkendara dan nitizen mampu memberikan wawasan serta sumber yang bisa dipertanggung jawabkan tanpa rekayasa.

\section{Memahami Tujuan}

Tujuan awal dari perancangan ini adalah menumbuhkan sikap bijak berkendara dengan media yang mudah diakses oleh masyarakat yang bersikap tanpa menggurui. Yang nantinya akan membantu masyarakat lain untuk mendapatkan ruang nyaman berkendara di jalan raya.

\section{Mengetahui Konteks}

Hal-hal yang akan terjadi kedepannya dalam perancangan ini, harapanya mampu mengeshare hasil dari perancangan berupa iklan yang dapat menimbulkan kesadaran bijak dalam berkendara.

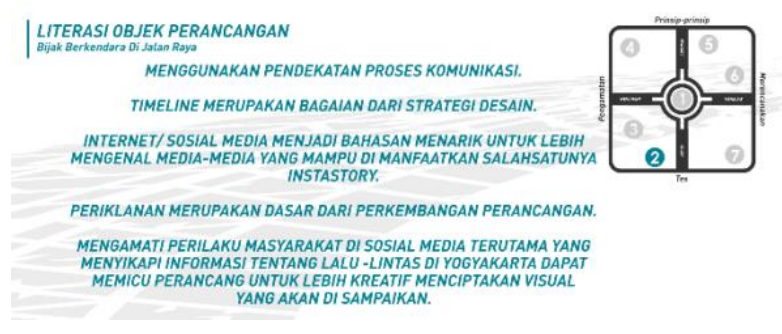

Gambar 4 "mengetahui konteks" Sumber: diptya aristo sahisnu

\section{Mengeksplorasi Konsep}

Asumsi-asumsi yang dapat dimapping mampu mengembangkan ide-ide lain saat ingin melakukan perancangan. Perancang memanfaatkan kejadian atau kasus yang ada di sosial media maupun secara fakta guna mendapatkan gagasan-gagasan menarik untuk divisualisasikanya.

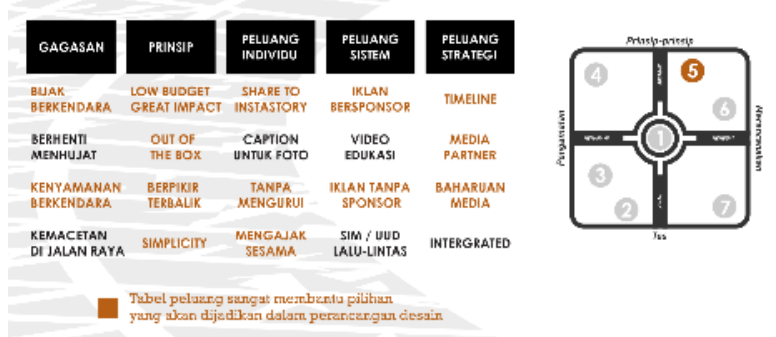

Gambar 5 "tabel peluang" Sumber: diptya aristo sahisnu

\section{Menyusun Solusi}

Menghadirkan peluang-peluang pilihan sangatlah dianjurkan, ide yang Nampak satu dapat dikembangkan menjadi beberapa untuk menjadi sebuah pilihan. 
Karena pilihan merupakan sumber solusi yang memberikan dampak lebih bagi perancangan guna kebutuhan dari masyarakat.

\section{Mengkomunikasikan}

beberapa

headline serta bodycopy agar pesan yang disampaikan tidak menjadi misskomunikasi visual. Membuat beberapa sample prototype dengan garis besar yang sama

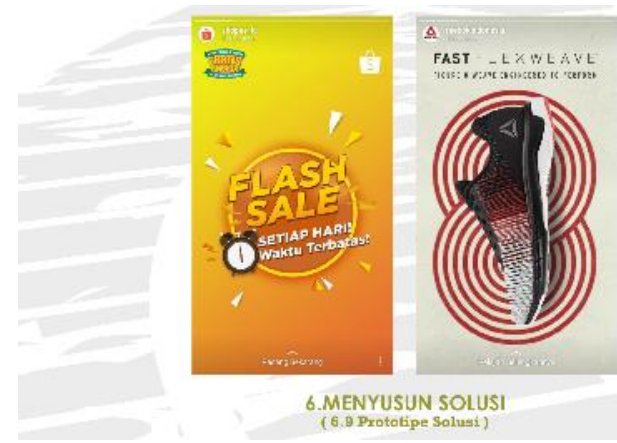

Gambar 6 "sample iklan Instagram" Sumber: iklan bersponsor

\section{Menyusun Gagasan}

Kelompok

bersinangungan sepertihalnya masyarakat dengan ICJ sangat pekat. Aktifvitas jalan yang mampu diakses melalui media sosial hingga mempermudah penguna untuk mendapatkan berita terkini. Polisi dengan masyarakat masih dipandang sebelah mata karena ada beberapa oknum yang memanfaatkan untuk tindakan yang seharusnya membimbing namun menghakimi. Polisi di mata ICJ lebih membantu untuk akses dalam menyelesaikan masalah guna mendapatkan solusi terbaik.

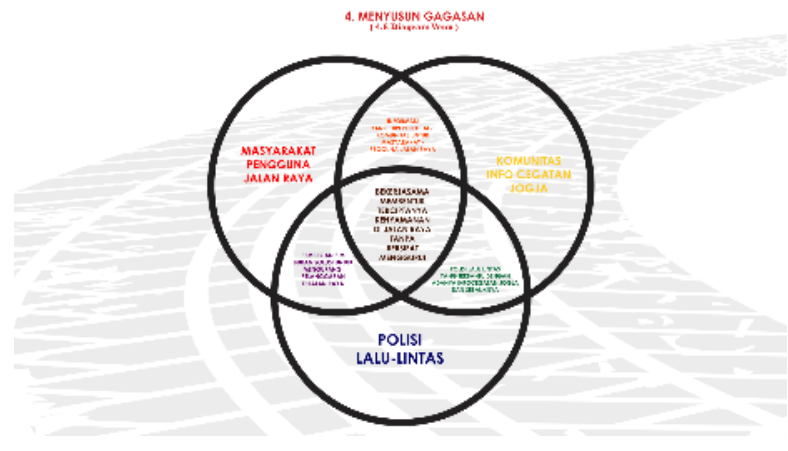

Gambar 7 "diagram venn" Sumber: diptya aristo sahisnu

\section{Merealisasikan Penawaran}

Berangkat dari sikap bijak berkendara yang disuport oleh komunitas terutama ICJ, informasi yang akan disampaikan berkesan tidak mengurui. Dengan menggunakan instastory yang akan di tayangkan di instagram menutup kemungkinan untuk memberikan setting no-comment dapat mengurangi perdebatan. Niat postingan yang mengembangkan iklan instastory bersoponsor nantinya hanya sebatas mengingatkan target audien saja.

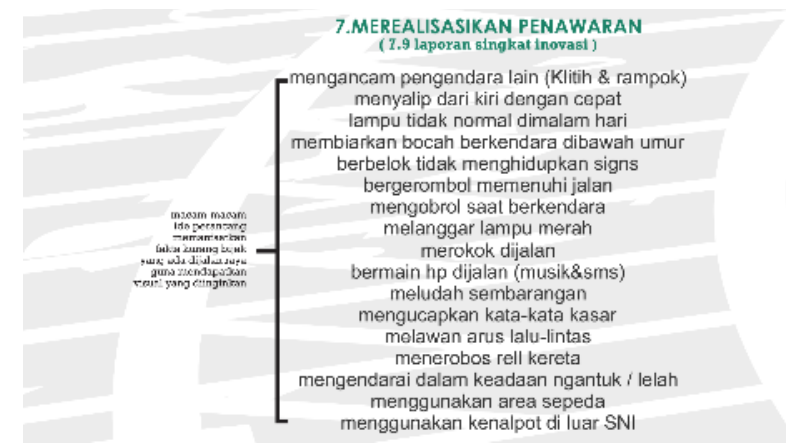

Gambar 8 "mapping idea prototype" Sumber: diptya aristo sahisnu 


\section{LANDASAN TEORI}

\section{Desain Komunikasi Visual}

Pemikiran desain komunikasi visual yang digunakan adalah yang memiliki konsep untuk mengarahkan cara berfikir dan membentuk tujuan dalam merancang konsep dan pesan perancangan. Mengutip pendapat A.D. Pirous yang ditulis oleh Sumbo Tinarbuko (2015: 8) dalam bukunya yang berjudul DEKAVE. Menurutnya desain komunikasi visual yang dalam bentuk kehadirannya seringkali perlu ditunjang dengan suara, suara pada hakikatnya adalah suatu bahasa. Tugas utamanya adalah membawakan pesan dari seseorang, lembaga, atau kelompok masyarakat tertentu kepada orang lain. Sebagai bahasa, maka efektifitas penyampaian pesan tersebut menjadi pemikiran utama seorang desainer komunikasi visual. Untuk itu, seorang desainer haruslah:

1. Memahami betul seluk beluk bentuk pesan yang ingin disampaikan.

2. Mengetahui kemampuan menafsir serta kecenderungan kondisi fisik maupun psikis kelompok masyarakat yang menjadi sasaran.

3. Harus dapat memilih jenis bahasa dan gaya bahasa yang serasi dengan pesan yang dibawakannya. Selain itu juga tepat untuk dibicarakan secara efektif, jelas, mudah, dan mengesankan bagi si penerima pesan.

\section{HASIL DAN PEMBAHASAN}

\section{Konsep Karya}

Penentuan konten karya dalam perancangan ini mengacu pada landasan teori yang dipakai, yang dihubungkan dengan segmentasi target audiens. Hasil sintesis dari teori dan target tersebut menghasilkan konten perancangan yang berisikan isi pesan dan bentuk pesan (pesan visual dan verbal).

Pada bulan Agustus 2016 lalu, Instagram membuat gebrakan baru pada update terbaru aplikasinya. Yaitu, dengan meluncurkan fitur stories yang hampir mirip seperti yang dimiliki Snapchat. Stories sendiri merupakan fitur update video dan foto yang akan tampil pada menu Stories dalam kurun waktu 24 jam. Dalam perancnagan bijak berkendara ini menggunakan instragam instastory dapat mengembangkan iklan secara meluas lebih cepat dan lebih efisien.

Saat Anda membuat iklan yang nanti muncul di Instagram Stories, pastikan untuk menggunakan video yang menarik atau gambar berkualitas tinggi dengan teks Call to Action (CTA) yang kuat dan sederhana. Ingat bahwa Anda hanya memiliki beberapa detik saja untuk membuat koneksi dengan pengguna. Instagram merekomendasikan agar Anda menggunakan ukuran gambar 1080 x 1920 dan aspek rasio 9:16. Jika Anda lebih suka menggunakan video daripada foto, pastikan video Anda dalam format .MOV, .MP4, atau .GIF dan durasi waktunya tidak lebih dari 15 detik.

\section{Isi Pesan}

Isi pesan yang disisipkan pada perancangan ini adalah, "bijaklah berkendara agar terciptanya rasa kenyamanan dijalan raya ." 


\section{Bentuk Pesan}

Setelah menentukan isi pesan, konten perancangan yang perlu untuk dirumuskan adalah bentuk pesannya. Dengan kata lain bagaimana pendekatan yang digunakan untuk menyampaikan isi pesan kepada target audiens. Bentuk pesan menggunakan pendekatan instastory yang menjelaskan suatu beberapa pesan yang bijak berkendara dan penjelasan mudah dipahami, didasarkan pada bentuk-bentuk kalimat larangan dan anjuran.

\section{Pesan Verbal}

Prinsipnya adalah perancangan menjadi sumber alternatif materi dan pedoman bagi masyarakat dan pengguna jalan raya untuk memberikan informasi dan saling mengingatkan sesama pengguna jalan raya Perancangan pesan menggunakan bahasa Indonesia yang diterapkan pada keseluruhan konten verbal. Menggunakan gaya penuturan yang umum dan lugas, artinya gaya bahasa yang biasa digunakan target audiens sehari-hari sehingga penyampaian dan penerimaan pesan menjadi lebih ramah.

\section{Pesan Visual}

\section{Logo}

Untuk membuat media perancangan memiliki identitas visual dan karakter, langkah pertama yang perlu dilakukan adalah dengan membuat rancangan logo/master design. Logo dibuat berdasarkan copy yang sudah ditentukan. Adapun konsep rancangan logo memiliki bentuk dan filosofi sebagai berikut:

1. Logo merupakan visualisasi dari bijak berkendara.
2. Jenis logo yang dirancang adalah wordmark, yakni logo yang didominasi oleh elemen tipografi.

3. Bentuk keseluruhan logo dibuat dinamis dan dekoratif, untuk memunculkan kesan ramah baca dan menarik perhatian.

4. Elemen-elemen visual yang melekat pada logo dibuat ekspresif dan berkarakter untuk menyesuaikan dengan karakter target audiens dan menekankan hastag.

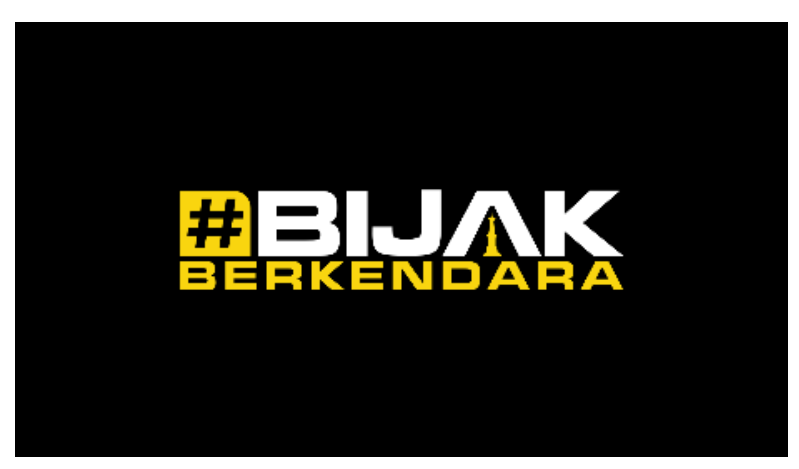

Gambar 9 Rancangan logotype terpilih Sumber: Dokumentasi penulis

\section{Ilustrasi}

Pemilihan jenis ilustrasi yang akan diterapkan adalah desain karakter laki-laki mengendarai sepeda montor yang ugalugalan bersifat mengingatkan untuk perilaku yang divisualkan tidak disarankan dijalan raya dan sangat merugikan pengguna jalan lain.

Desain karakter dirancang untuk membuat target audiens lebih mudah menyerap pesan dan menjiwai karakternya. Desain karakter laki-laki karena mengingatkan bahwa pelanggaran yang sering terjadi berdasarkan riset adalah lakilaki. Keseluruhan desain karakter terdiri dari 5 slide ilustrasi yang digabungkan menjadi video durasi pendek, Sebagai pengingat berkendara dan media partner yang akan di tampilkan di akhir slide. Layout 
untuk bagian dari awal sampai akhir lebih menampilkan susasana jalanan.

Oleh karena itu menyampaikan pesan melalui pendekatan cerita deskriptif yang dilengkapi ilustrasi akan lebih membuat target audiens tertarik untuk mengakses media dan memudahkan dalam proses interpretasi pesan.

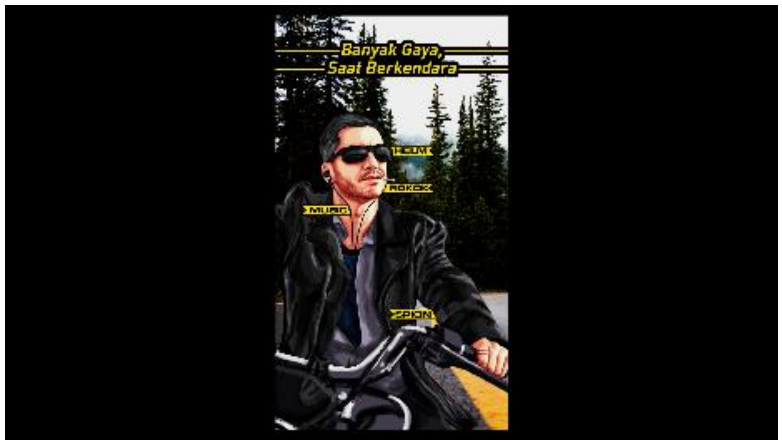

Gambar 10Salah satu slide karya Sumber: Dokumentasi penulis

\section{GSM ( graphic standard manual)}

Graphic standard manual merupakan salah satu element penting dalam membangun citra \& branding. Dalam hal ini identitas bijak berkendara secara kedepan tidak dapat berdiri sendiri karena pola-pola yang telah ada akan bersinangungan dengan komunitas Info Cegatan Jogja dan pihak berwenang kepolisian.

Karya yang akan ditampilkan pun akan mendapatkan support lebih dari media partner, agar tidak merusak visual yang dibangun maka terciptalah GSM. Berikut beberapa GSM yang telah dibuat guna tidak mengurangi unsur readybility, legadibility, dan selalu ada penjelasan disetiap bentuknya. Menggunakan graphic standard manual mampu mempermudah penggunaan logo pada beberapa media oleh media partner.

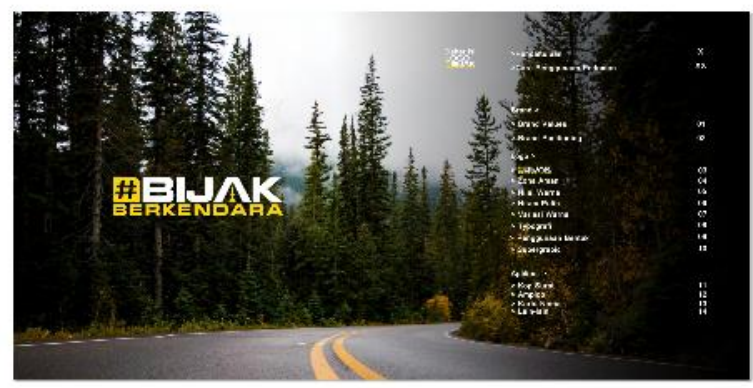

Gambar 11GSM ( Graphic Standard Manual) Sumber: Dokumentasi penulis

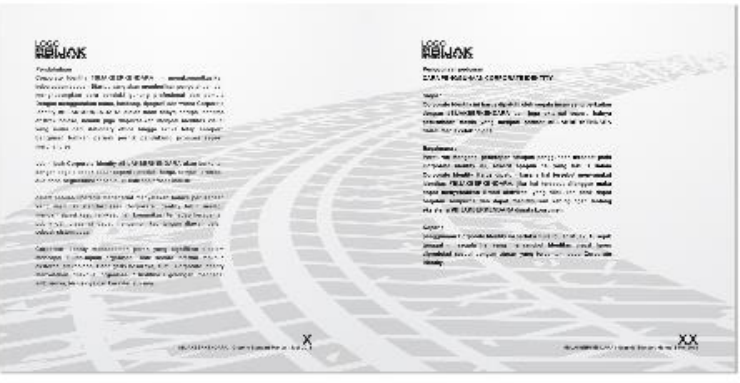

Gambar 12GSM (Graphic Standard Manual) Sumber: Dokumentasi penulis

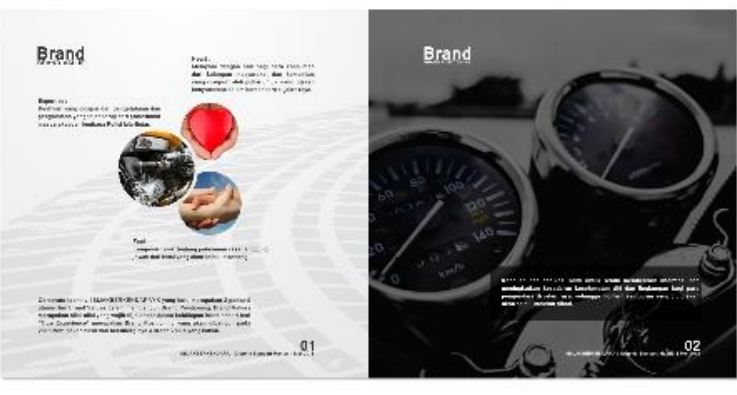

Gambar 13GSM (Graphic Standard Manual) Sumber: Dokumentasi penulis

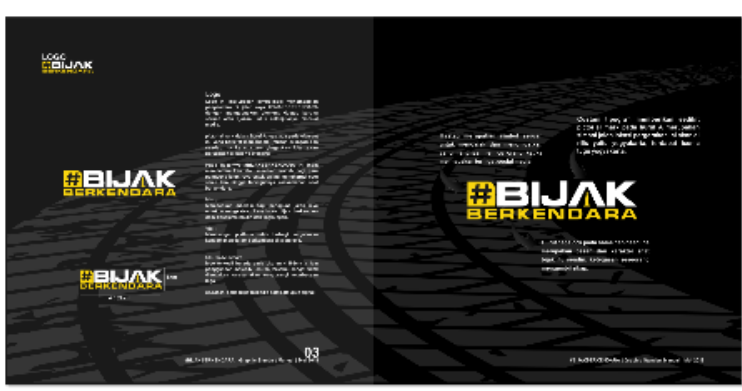

Gambar 14GSM (Graphic Standard Manual) Sumber: Dokumentasi penulis 


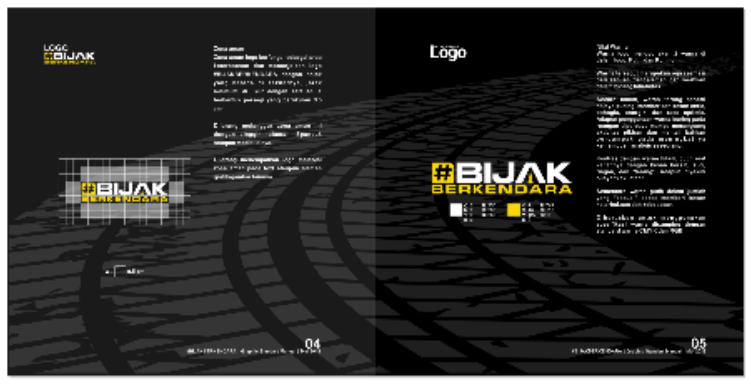

Gambar 15GSM (Graphic Standard Manual) Sumber: Dokumentasi penulis

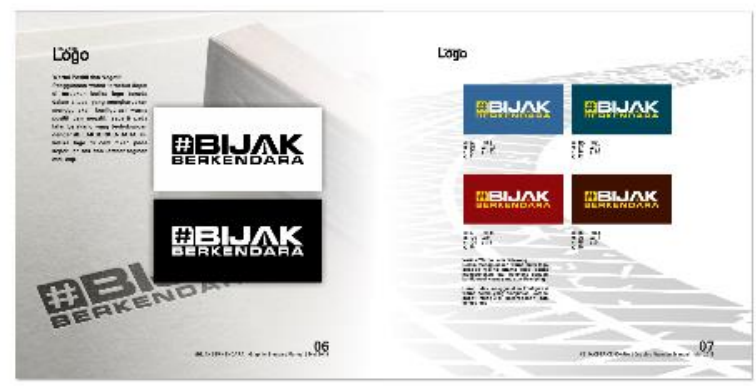

Gambar 16GSM (Graphic Standard Manual) Sumber: Dokumentasi penulis

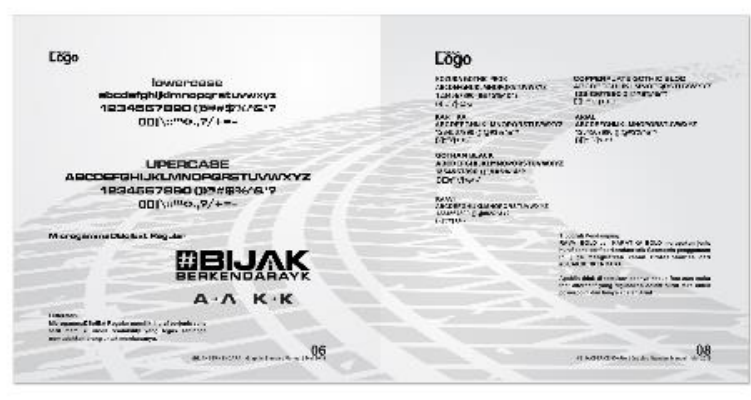

Gambar 17GSM (Graphic Standard Manual) Sumber: Dokumentasi penulis

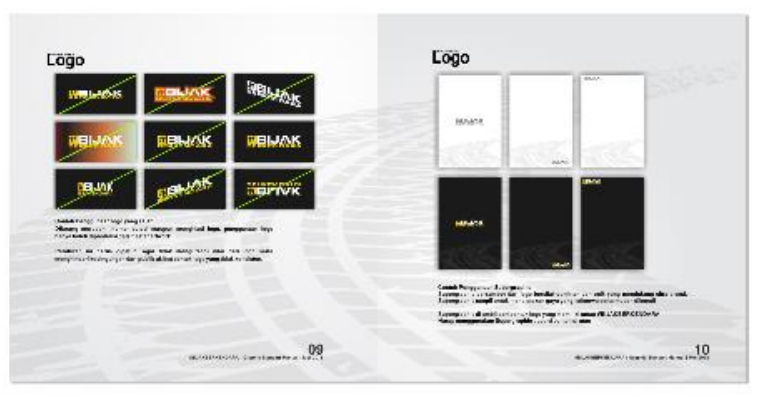

Gambar 18GSM (Graphic Standard Manual) Sumber: Dokumentasi penulis

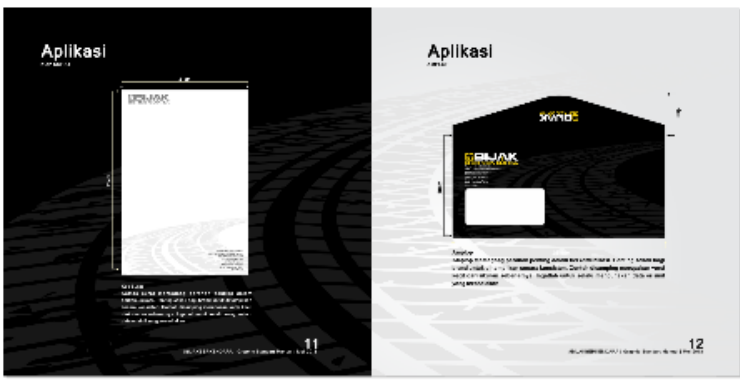

Gambar 19GSM ( Graphic Standard Manual) Sumber: Dokumentasi penulis

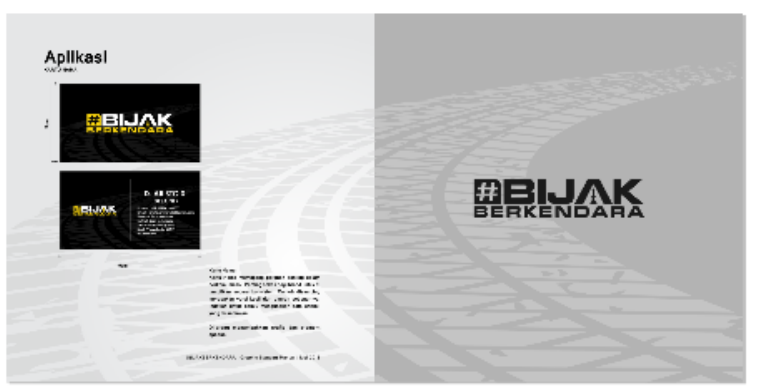

Gambar 20GSM (Graphic Standard Manual) Sumber: Dokumentasi penulis

\section{Strategi Media}

Strategi media merupakan kegiatan menentukan media-media yang menjadi prioritas dan sebagai pendukung media utama agar dengan mudah menjangkau target audiens yang sudah ditentukan segmentasinya. Memilih sebuah media yang tepat serta dapat menyesuaikan dengan kebutuhan, terutama media-media yang sering bersinggungan dengan target audiens. Maka dalam strategi menentukan media pendukung haruslah tepat, efektif, dan juga efisien.

Perancangan ini memilih instastory untuk media utama dan memilih beberapa media partner agar pesan yang disampaikan tidak bersifat mengurui 


\section{VISUALISASI}

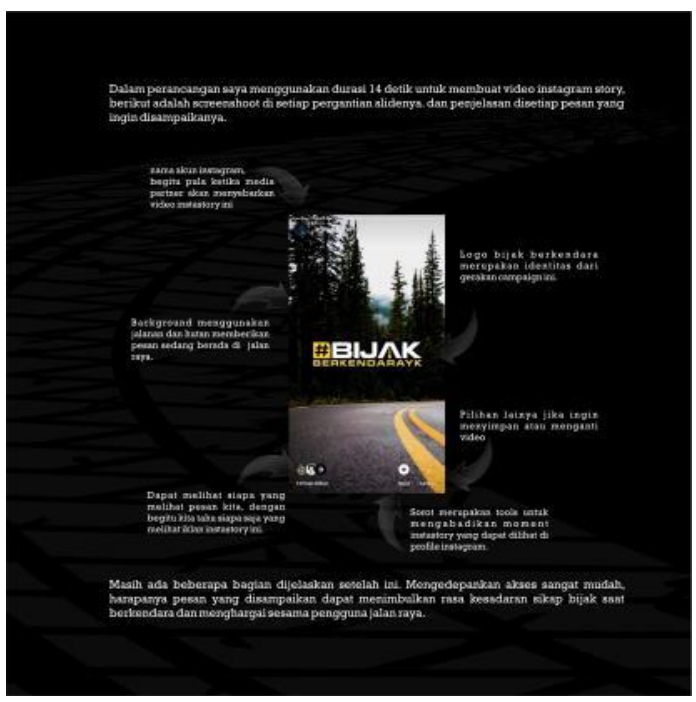

Gambar 21Slide 1 iklan instastory Sumber: Dokumentasi penulis

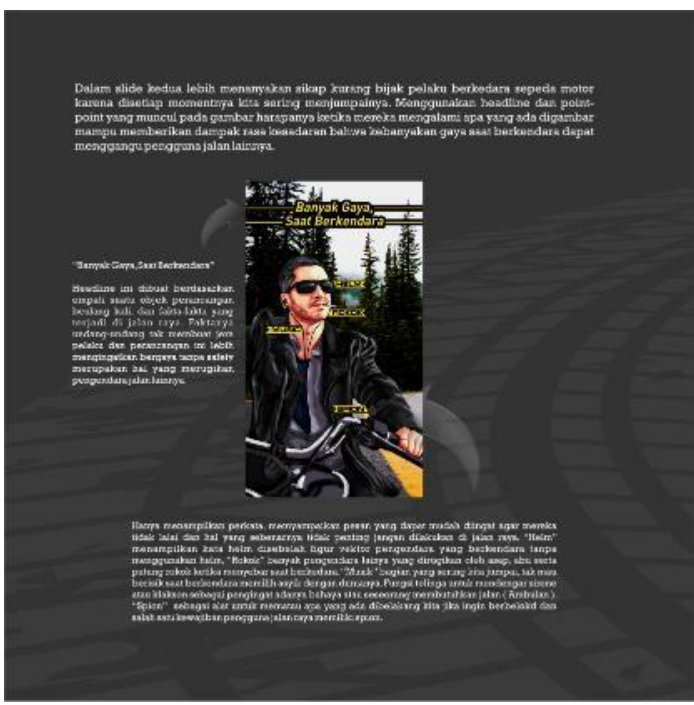

Gambar 22Slide 2 iklan instastory Sumber: Dokumentasi penulis

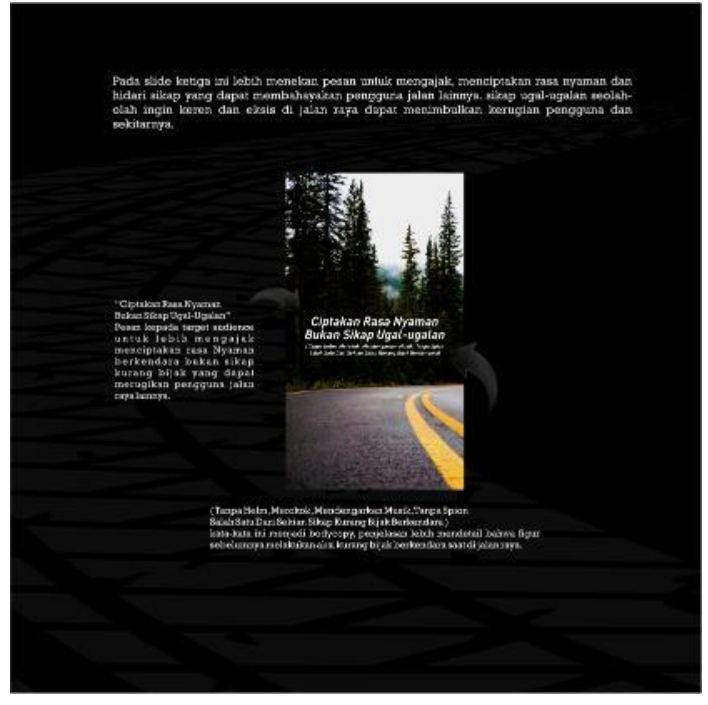

Gambar 23Slide 3 iklan instastory Sumber: Dokumentasi penulis

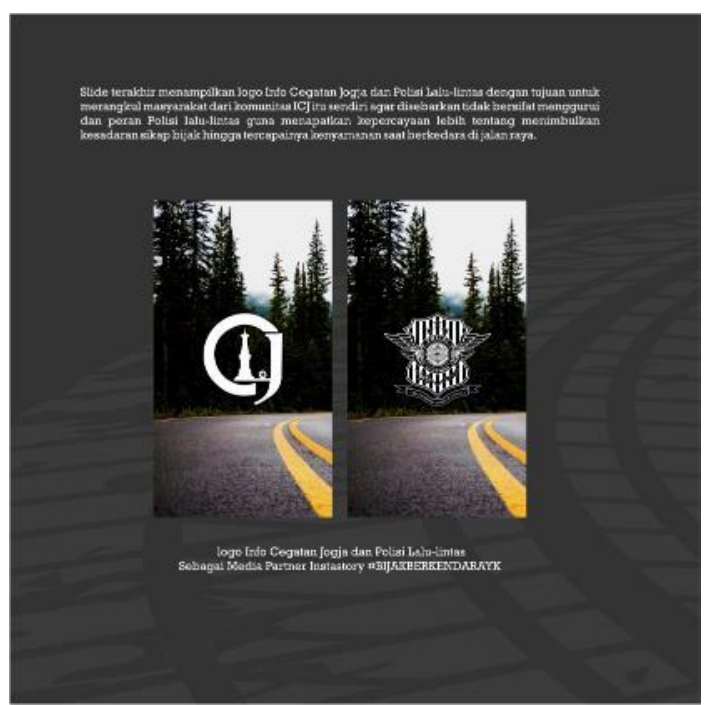

Gambar 24Slide 4-5 iklan instastory Sumber: Dokumentasi penulis

\section{KESIMPULAN}

Perancangan ini lebih menekankan pola masyarakat, tanpa merubah sistem yang telah ada. Sikap bijak berkendara dapat berdampak keseluruh kalangan pengguna jalan raya. Dengan menggunakan pendekatan analisis metode vijay kumar perancangan ini mampu menganalisis lebih mendalam. Melihat kebiasaan masyarakat dengan terjun langsung sikap empati maka 
perancang memperoleh stimulus untuk menemukan solusi.

Pemilihan media instagram, anda bisa menceritakan sebuah cerita dan mempromosikan bisnis anda menggunakan opsi iklan foto platform: iklan foto, iklan video, iklan carousel, dan sekarang fitur terbaru, iklan di instagram stories.lebih dari 150 juta akun menggunakan instagram stories setiap hari. Menggunakan instagram stories adalah cara yang hebat bagi sebuah bisnis untuk berinteraksi dengan follower mereka dan meningkatkan kesadaran merek (brand awareness).

Dengan iklan instagram stories, bisnis anda bisa terus eksis dilihat oleh para follower dan mendapatkan penggemar baru untuk instagram bisnis atau merk anda. Harpanya ketika campaign ini mulai di launcing maka akan terciptanya kesadaran saat menggunakan jalan raya. Tidak melakukan sikap kurang bijak dan ugalugalan. Memanfaatkan media partner info cegatan jogja guna menjembatani masyarakat dan tak lepas dari pantauan polisi lalu-lintas.

\section{DAFTAR PUSTAKA}

\section{Jurnal}

[1] Bigelow, James dan Ami Poremba. (2014). “Achilles' Ear? Inferior Human Short-Term and Recognition Memory in the Auditory Modality". PLoS One 9: e89914. 26 Februari 2014

\section{Karya IImiah}

[1] Fauzan, Nur Aji. (2017), "Perancangan Buku Ilustrasi Kumpulan Hadits Pilihan Bagi Anak Dalam Kegiatan Sehari-Hari”. Yogyakarta: Fakultas Seni Rupa, Institut Seni Indonesia Yogyakarta

\section{Buku}

[1] Bungin, Burhan. (2006), Sosiologi Komunikasi Teori, Paradigma, dan Diskursus Teknologi Komunikasi Di Masyakarat. Jakarta : Kencana Prenanda Media Group

[2] Brown, Tim. (2009). Change By Design, New York: HarperCollins

[3] Hakim, Budiman. (2018). Story Telling! Beriklan Lewat Cerita, Yogyakarta: Galang Pustaka

[4] Hermawan, Agus. (2012), Komunikasi Pemasaran, Penerbit Erlangga, Jakarta

[5] Kumar, Vijay (2013), 101 Metode Desain Pendekatan Terstruktur Untuk Inovasi Di Organisasi Anda, terjemahan Christin Irene. (2016) Jakarta : Penerbit Elex Media Kompeterindo

[6] Kotler, Philip. (1988), Marketing Management, Sixth Edition : Analysis, Planning, Implementation, and Contorol atau Management Pemasaran, Edisi Keenam: Analisis, Perencanaan, Implemetasi dan Pengendalian, Terjemahan Drs. Jaka Wasana, MSM, Penerbit Erlangga, Jakarta

[7] Lawson, Bryan. (1980), How Designers Think atau Bagaimana Cara Berpikir Desainer, terjemahan Harafiyah Widiawati. (2007), Jalasutra, Yogyakart

[8] Maharsi, Indiria. (2016). Ilustrasi, Yogyakarta: Badan Penerbit ISI Yogyakarta

[9] Sanyoto, Sadjiman Ebdi. (2010). Nirmana Elemen-Elemen Seni dan Desain, Yogyakarta: Jalasutra

[10]Sihombing, Danton. (2015). Tipografi dalam Desain Grafis, Jakarta: Gramedia Pustaka Utama

[11] Tinarbuko, Sumbo. (2015). DEKAVE Desain Komunikasi Visual - Penanda Zaman Masyarakat Global, Yogyakarta: CAPS Center for Academic Publishing Service

[12] Tinarbuko, Sumbo. (2017). Membaca Tanda dan Makna Desain Komunikasi 
Visual, Yogyakarta: Badan Penerbit ISI Yogyakarta

[13]Watono, A. Adji \& Maya C. Watono. (2011), IMC Integrated marketing communication that Sells : Bring Your Brand to the Top with Indonesia Style Communication, PT Gramedia, Jakarta.

\section{Situs Web}

[1] Biru, Nagablog (2012), DATA SEKUNDER DAN DATA PRIMER, Last accesed on 12 Juni, 2009 at url

[2] https://nagabiru86.wordpress.com/20 09/06/12/data-sekunder-dan-dataprimer

[3] Borreli, Lizzete. (15 Mei 2015). Hello My Name Is: Why Humans Are Better At facial Recognition Than Remembering Names. Diakses 31 Mei 2018 dari http://www.medicaldaily.com/pulse/h ello-my-name-why-humans-are-betterfacial-recognition-rememberingnames-333598

[4] InkBot Design. (28 Maret 2018). Logotype vs Logomark Design - What's the Difference. Diakses 5 Juni 2018 dari https://inkbotdesign.com/logotype-vslogomark/

[5] Palupi, Dtag Hasto(2014), Rahasia Kesuksesan Bran activation [online]. Diakses

Desmber2015:http://mox.co.id/headli ne/rahasia kesuksesan-bran-activation 